\title{
$\beta$-Confident-registry: aiming to be largest-ever studied cohort of cryopyrin-associated periodic syndromes (CAPS) patients. Study design and baseline characteristics
}

\author{
J Kuemmerle-Deschner ${ }^{1 *}$, D Rothenbacher ${ }^{2}, \mathrm{U} \mathrm{Walker}^{3}, \mathrm{H} \mathrm{Tilson}^{4}, \mathrm{H} \mathrm{Hoffman}^{5}, \mathrm{P} \mathrm{Hawkins}^{6}$ \\ From 18th Pediatric Rheumatology European Society (PReS) Congress \\ Bruges, Belgium. 14-18 September 2011
}

\section{Background}

Clinical data, especially long-term follow-up, is limited in CAPS due to its extreme rarity. We report here the design of a global observational registry for canakinumab (Ilaris $\left.{ }^{\mathbb{B}}\right)$. The registry is monitored by an external steering committee with expertise in auto-inflammatory disease and registry design.

\section{Aim}

The primary objective is to monitor overall safety of routine care with canakinumab in a large cohort $(\mathrm{N} \geq 400)$ of CAPS patients. Secondary objectives include exploring growth and development patterns in children and to measure the long-term impact of canakinumab on disease progression.

\section{Methods}

CAPS patients receiving canakinumab as part of their routine care are included in this study for a minimum of 5-years follow-up. Data from routine clinic assessments is supplied at 6-monthly intervals via a web-based application. Selected safety events potentially associated with anti-IL-1 therapy such as serious infections, malignancies, hypersensitivity and disease activity/progression is analyzed. Signs and symptoms of systemic inflammation, neurologic and ophthalmologic status and the

Table 1

\begin{tabular}{|c|c|c|c|c|}
\hline & FCAS $(n=10)$ & MWS $(n=37)$ & $\operatorname{NOMID}(n=6)$ & Other $(n-5)$ \\
\hline Age $<4$ years & 0 & 2 & 1 & 1 \\
\hline Age $4-<18$ years & 2 & 6 & 3 & 1 \\
\hline Age $\geq 18$ years & 8 & 29 & 3 & 3 \\
\hline Male, n (\%) & $3(30.0)$ & $20(54.1)$ & $3(50.0)$ & $2(40.0)$ \\
\hline NLRP3 mutation, $\mathrm{n}(\%)$ & $10(100.0)$ & $35(94.6)$ & $5(83.3)$ & $2(86.7)$ \\
\hline Disease duration (months, mean) & 550 & 370 & 172 & 64 \\
\hline Rash/arthralgia/headache/conjunctivitis (\%) & $100 / 100 / 50 / 80$ & $97.3 / 97.3 / 78.4 / 75.7$ & $100 / 100 / 93.4 / 66.6$ & $80 / 100 / 20 / 40$ \\
\hline History of anaemia (\%) & 10 & 8.1 & 50 & 0 \\
\hline Prior SAA value (mean, mg/L) & 37 & 26 & 47 & 3 \\
\hline Prior IL-1 inhibitor treatment, $\mathrm{n}(\%)$ & 0 & $14(37.8)$ & $1(16.1)$ & $2(40)$ \\
\hline
\end{tabular}

\footnotetext{
* Correspondence: kuemmerle.deschner@uni-tuebingen.de

'Division of Pediatric Rheumatology, University Hospital Tuebingen,

Tuebingen, Germany

Full list of author information is available at the end of the article
} 
potential for canakinumab therapy to prevent amyloidosis and to ameliorate sensorineural deafness are assessed. Patterns of growth/development, pregnancies, outcomes of vaccination, dosing pattern and tolerability are ascertained. All patients are followed until the registry ends.

\section{Results}

Baseline data from the first 60 CAPS patients, including 15 pediatric patients (age $<18$ years), enrolled to date, are presented in table 1 .

\section{Conclusion}

Baseline characteristics of the 60 patients enrolled to date demonstrate an expected disease background. Upon availability of a larger data-set, subanalyses will yield valuable insights into disease characteristics and modification properties of canakinumab.

\section{Author details}

'Division of Pediatric Rheumatology, University Hospital Tuebingen, Tuebingen, Germany. ${ }^{2}$ Novartis Pharma AG, Basel, Switzerland.

${ }^{3}$ Rheumatologische Universitäts-Poliklinik, Basel, Switzerland. ${ }^{4}$ University of North Carolina, Chapel Hill, NC, USA. ${ }^{5}$ Division of Rheumatology and Allergy/ Immunology, University of California at San Diego, USA. ${ }^{6}$ Department of Medicine, University College London Medical School, London, UK.

Published: 14 September 2011

doi:10.1186/1546-0096-9-S1-P16

Cite this article as: Kuemmerle-Deschner et al:: $\beta$-Confident-registry: aiming to be largest-ever studied cohort of cryopyrin-associated periodic syndromes (CAPS) patients. Study design and baseline characteristics. Pediatric Rheumatology 2011 9(Suppl 1):P16.

\section{Submit your next manuscript to BioMed Central} and take full advantage of:

- Convenient online submission

- Thorough peer review

- No space constraints or color figure charges

- Immediate publication on acceptance

- Inclusion in PubMed, CAS, Scopus and Google Scholar

- Research which is freely available for redistribution

Submit your manuscript at www.biomedcentral.com/submit 